\title{
B7 - Avaliação do desempenho do cultivo em suspensão de cé- lulas CHO expressando a EPOhr em sete meios comerciais
}

Alexandre Borges Murad ${ }^{1 *}$; Tiago Pereira dos Santos'; Esther Vinhais Gutierrez ${ }^{1}$; Maíra Peixoto Pellegrini ${ }^{1}$; Marina Vergne de Almeida ${ }^{1}$; Álvaro Paiva Braga de Sousa ${ }^{1}$; Rodrigo Coelho Ventura Pinto ${ }^{1}$.

\section{1 - Bio-Manguinhos/Fiocruz}

\section{Introdução:}

O avanço das técnicas de biologia molecular possibilitou o emprego de cultivos celulares como importante plataforma para a produção, através de processos biotecnológicos, de proteínas recombinantes terapêuticas (biofármacos). A manutenção das condições ideais de cultivo é de grande importância para a obtenção do produto conforme especificações de qualidade e requisitos de segurança. Desta forma, os meios de cultivo promovem o ambiente e fornecimento de nutrientes ideais às células, garantindo o funcionamento normal do metabolismo, do crescimento celular e a correta síntese do produto de interesse. Em um processo produtivo, este insumo deve ser tratado de forma criteriosa, cuidando que o seu fornecimento seja constante e invariável do ponto de vista da sua composição. A disponibilidade de alternativas validadas que garantam a manutenção das especificações de qualidade do produto torna-se então uma estratégia essencial para evitar o desabastecimento.

\section{Objetivo:}

Comparar diferentes meios de cultivo comerciais, livres de soro fetal bovino e componentes animais, com o meio de cultivo controle atualmente utilizado para o cultivo em suspensão de células $\mathrm{CHO}$ secretoras de EPOhr, analisando a promoção de crescimento celular, produção de EPOhr e metabolismo.

\section{Metodologia:}

Os experimentos foram realizados com células $\mathrm{CHO}$ secretoras de EPOhr, a partir do descongelamento de criotubos de um banco de células de trabalho. As células foram adaptadas em diferentes meios de cultivo utilizando frascos estáticos e garrafas rotatórias. Ao final da etapa de adaptação, foram realizadas cinéticas comparativas dos meios testados em comparação ao meio controle. As cinéticas foram comparadas mediantes fatores metabólicos e proliferativos do cultivo observados. 


\section{Resultados:}

Dos sete meios testados, somente 2 meios ( $\mathrm{HyCell}^{\mathrm{TM}}$ e TransFx-C) não responderam bem à adaptação direta, impossibilitando a avaliação cinética. Entre os meios que responderam satisfatoriamente à adaptação, 3 apresentaram condições melhores ou iguais ao do meio controle: SFM4CHO ${ }^{\mathrm{rm}}$ - Utility. Os meios $\mathrm{SFM}_{4} \mathrm{CHO}^{\mathrm{TM}}$ e Cellvento ${ }^{\mathrm{TM}} \mathrm{CHO}-110$ apresentaram melhores capacidades de promoção de crescimento $(2,42 \times 106$ células $/ \mathrm{mL}$ e 4,6x106 células/mL, respectivamente), enquanto o meio $\mathrm{CPCHO}^{\mathrm{ma}}$ foi capaz de promover uma maior produtividade e taxa específica média de formação de EPOhr $(\mathrm{P}=12,16 \mu \mathrm{g} /$ dia e $\mathrm{qEPOhr}=7,3 \mu \mathrm{g} / 106$ células/dia, respectivamente).Os meios de cultivo $\mathrm{SFM}_{4} \mathrm{CHO}^{\mathrm{TM}}$ e Cellvento ${ }^{\mathrm{TM}} \mathrm{CHO}-110$ apresentaram boa capacidade de promover crescimento celular com concentração máxima de células viáveis/mL superior ao meio controle, indicando possuir melhor crescimento celular. O meio $\mathrm{CPCHO}^{\mathrm{Tm}}$ apresentou melhor produção de EPOhr, em comparação ao meio de cultivo controle.

\section{Conclusão:}

Os resultados mostraram que 3 meios apresentaram condições melhores ou semelhantes ao meio controle. Sugere-se que o meio SFM4CHO, que apresentou resultados mais semelhantes ao meio controle, apresentaria também menor alteração do perfil bioquímico do produto, no entanto esta teoria somente poderá ser comprovada mediante análise aprofundada da molécula de EPOhr purificada.

Palavras-Chave: Células $\mathrm{CHO}$ secretoras de EPOhr; Eritropoetina; Meio de Cultivo 